\title{
Epidemiological investigation of a food poisoning outbreak: a study among hostel dwelling students and resident doctors of a tertiary healthcare facility of India
} Chandramani Singh ${ }^{1}$, Bijit Biswas ${ }^{2}$, Naveen $\mathrm{KG}^{3}$, Haripriya Hari ${ }^{3}$, Sanjay Pandey ${ }^{4}$, Bijaya Nanda Naik ${ }^{5}$

${ }^{1}$ Professor and Head, Department of Community and Family Medicine, All India Institute of Medical Sciences, Patna, Bihar; ${ }^{2}$ Senior Resident, Department of Community and Family Medicine, All India Institute of Medical Sciences, Patna, Bihar; ${ }^{3} \mathrm{Junior}$ Resident, Department of Community and Family Medicine, All India Institute of Medical Sciences, Patna, Bihar; ${ }^{4}$ Additional Professor, Department of Community and Family Medicine, All India Institute of Medical Sciences, Patna, Bihar; ${ }^{5}$ Assistant Professor, Department of Community and Family Medicine, All India Institute of Medical Sciences, Patna, Bihar.

\begin{tabular}{|c|c|c|c|c|c|c|c|}
\hline Abstract & Introduction & Methodology & Results & Conclusion & References & $\underline{\text { Citation }}$ & Tables/ Figures \\
\hline
\end{tabular}

\section{Corresponding Author}

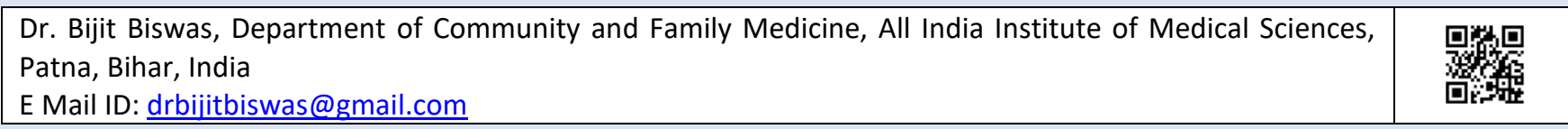

\section{Citation}

Singh C, Biswas B, Naveen KG, Hari H, Pandey S, Naik BN. Epidemiological investigation of a food poisoning outbreak: a study among hostel dwelling students and resident doctors of a tertiary healthcare facility of India. Indian J Comm Health. 2021;33(3):480-485. https://doi.org/10.47203/IJCH.2021.v33i03.013

Source of Funding: Nil Conflict of Interest: None declared

Article Cycle

Received: 03/03/2021; Revision: 08/07/2021; Accepted: 12/08/2021; Published: 30/09/2021

This work is licensed under a Creative Commons Attribution 4.0 International License.

\section{Abstract}

Background: During second week of February, 2021 several cases of food poisoning were reported from hostels of a tertiary healthcare facility, thus this epidemiological investigation was undertaken, to confirm existence of a food poisoning outbreak, describe cases as per person, place, time and predominant food source, identify the attributes associated with the outbreak. Methods: To investigate the suspected food poisoning outbreak, an online unmatched case control study was conducted among 440 hostel dwelling students and resident doctors of a tertiary healthcare facility of eastern India during February, 2021. Results: The proportion of the study subjects who reported to have experienced food poisoning symptoms was $23.9 \%$. Most of the food poisoning event reported to have occurred during 10th February, 2021 (26.6\%). In the multivariable logistic regression model, predominant consumption of food from girls' hostel mess [adjusted odds ratio (AOR): 7.83 (1.58-38.79)] and canteen 1 [AOR: 4.83 (1.13-20.69)] were found to be multivariable predictors of food poisoning events adjusted with age, gender, designation and residing hostel. Conclusion: One in every four study participants opined to have experienced food poisoning symptoms during the study period. This confirmed the existence of a multi-source food poisoning outbreak in the study population.

\section{Keywords}

Disease Outbreaks; Foodborne Diseases; Epidemiological Investigation; Students; Resident Doctors; Vomiting

\section{Introduction}

South Asian region contributes a major chunk of globally reported food-borne illnesses.(1) Food poisoning is a food borne illness of global public health concern which often goes unreported even in developed countries.(2) Aetiology of food poisoning may be viral, bacterial, protozoal or toxin associated.(1,3) It takes hours or sometimes even days to develop symptoms of food poisoning after consumption of contaminated food. Some common symptoms of food poisoning are diarrhoea, upset stomach, abdominal cramps, nausea, vomiting, fever etc.(4)
Identification of pattern, source and causative organism of food poisoning outbreaks may prove to be invaluable in designing interventions to in curb these outbreaks. $(5,6,7)$ In India food borne illnesses along with acute diarrhoeal diseases constituted half of the total reported outbreaks during the years 2011-2015.(5) During second week of February, 2021 several cases with food poisoning like symptoms were reported from hostels of a tertiary healthcare facility in eastern India. In response the present survey was conducted among hostel dwelling students and resident doctors to confirm existence and pattern of the reported food poisoning cases. 


\section{Aims \& Objectives}

To confirm existence of a food poisoning outbreak, describe cases as per person, place, time and predominant food source, identify the attributes associated with the outbreak among hostel dwellers of a tertiary healthcare facility of eastern India.

\section{Material \& Methods}

Study type: Unmatched case control study.

Study Population: Hostel dwelling students and resident doctors of a tertiary healthcare facility. Those who have suffered from food poisoning during the study period were deemed as cases while others were the controls.

Study Area: Hostels of a tertiary healthcare facility at Patna, Bihar, India.

Study Duration: February, 2021.

Sample size: Out of 629 hostel dwellers 440 (69.9\%) participated on the survey.

Inclusion criteria: Any student (medical/ nursing), intern and resident doctor living in the hostels during the study period were eligible.

Exclusion criteria: Those who did not agreed to participate were excluded.

Sampling method: Complete enumeration method.

Strategy for data collection: The data collection was done using google form. The study google form link was circulated among students and residents individually and in groups using 'WhatsApp'.

Study tool: A structured questionnaire was used for the survey. It contained 4 sections. Section 1 (description of the study aim and consent): do you voluntarily agree to participate in the study (agree/ disagree). Those who agreed continued to next section while who disagreed for them the survey ended there itself. Section 2 (background characteristics): age, sex, designation, hostel number, predominant source of food, history of food poisoning related symptoms (i.e., nausea/ vomiting and abdominal cramps and/or loose stools) in last 15 days (yes/ no). Those who said 'yes' they continued to the next section while those who reported it to be 'no' for them the survey ended here. Section 3 (illness characteristics): presenting symptom, other symptoms during the event, date and time of onset of symptoms, hospitalisation requirement, treatment taken, details of lab investigation done during the event, date and time of remission of symptoms, could suspect causative food item and/ or its source (yes/no). Those who said 'yes' they continued to the next section while those who reported it to be 'no' for them the survey ended here. Section 4 (details of the suspected food and its source): name and source of the suspected food item, date and time of consumption.

Working definition: A food poisoning case: Those opined to have suffered from nausea/ vomiting and abdominal cramps and/or loose stools during the last 15 days were considered as a food poisoning case.
Predominant source of food: To elicit this variable we have asked "what is your predominant source of food in last 15 days?"

Ethical issues: Online informed consent of each study participant was documented before administration of the study questionnaire. Ethical approval of Institutional Ethics Committee (IEC) of All India Institute of Medical Sciences (AlIMS), Patna was taken (Ref. No: AlIMS/Pat/IEC/2020/668) prior to communication of the research for publication. The study followed all the principles of declaration of Helsinki.

Statistical Analysis: Statistical package for social sciences (SPSS) (version 22.0) (Chicago, USA) was used for analytical and inferential statistics employed in the study. Continuous variables were reported using mean (SD) and median [interquartile range (IQR)] while frequency (percentage) was used to report categorical variables. Univariate and multivariable logistic regression analysis was done to identify factors associated with the food poisoning events. The strength of association between food poisoning and its various attributes was expressed in terms of odds ratio (OR) at $95 \%$ confidence limit. For all inferential statistics level of significance was set at $p<0.05$.

\section{Results}

Background characteristics, predictors of food-poisoning events: Mean age of the study participants was 21.9 years with median (IQR) of 21 (20-24) years. Overall, $23.9 \%$ of the study participants have experienced symptoms of food-poisoning during the study period. Most of the food poisoning event reported to have occurred during 10th February, 2021 (26.6\%). Girls' (35.2\%) and boys' (33.3\%) hostel mess were associated with majority of the food poisoning events. In the multivariable logistic regression model, predominant consumption of food from girls' hostel mess [adjusted odds ratio (AOR): 7.83 (1.58-38.79)] and canteen 1 [AOR: 4.83 (1.13-20.69)] were found to be multivariable predictors of food poisoning events adjusted with age, gender, designation and residing hostel. Overall, the independent variables predicted $11.4 \%$ variability of the food poisoning events with predictive accuracy rate of $77.5 \%$. An insignificant Hosmer Lemeshow test $p$-value (.935) ensured model fit. (Table 1 ) and (Figure 1)

Illness characteristics of the study subjects with food poisoning: The median duration of illness was 2 days [IQR: 1-3 days; range: $0-8$ days] with $12.4 \%$ reported recovery on the same day. In the suspected food items, one-third (33.3\%) have given unspecific response (i.e., lunch, dinner, oily food etc.) while $15.7 \%, 11.8 \%$ and $9.8 \%$ have reported it to be chicken items (i.e., chicken curry, chilli chicken etc.), bread items (i.e., bhatura, naan, breads etc.) and potato items (i.e., chokha, bhujia, sabji etc.) respectively. The median duration between consumption of suspected food item and appearance of symptoms (incubation 
period) (IP) was 8 hours (IQR: 6-12 hours). (Table 2) and (Figure 2)

\section{Discussion}

In the present multi source food poisoning outbreak one in every four study subjects had experienced symptoms of food poisoning with those who predominantly consumed food from girls' hostel mess and canteen 1 had significantly higher odds of developing symptoms of food poisoning during the study period.

In the present epidemiological outbreak investigation, we found that $23.9 \%$ of the study participants have experienced food poisoning related symptoms during the study period. This was less compared to a study in a girls hostel of a medical college in Punjab by Prajapati et al.(8) where $70.1 \%$ of the girl students have experienced food poisoning related symptoms of food poisoning after taking a common dinner at hostel mess. Another food poisoning outbreak investigation among inmates of a private women's hostel by Damodharan et al.(9) reported $65.8 \%$ attack rate after consuming a common meal which was more compared to us. The difference in observations might be because both these studies investigated common source (mess) food poisoning whereas we investigated food poisoning events of hostel dwellers with diverse food source. A online survey conducted among random sample of hostel dwellers of Chennai by Vidyashri et al.(10) reported high incidence of food poisoning (69.0\%). Thus, food poisoning is a common health issue faced by hostel dwellers which needs early identification and prompt action.

Considering clinico-epidemiological profile of the reported cases Clostridium perfringens or Bacillus Cereus seemed to be associated with most of these food poisoning cases. This is being suspected based on reported incubation period [median (IQR): 8 (8-16) hours], clinical picture of the cases [loose stools $(77.1 \%)$ and abdominal cramps $(72.4 \%)$ being the most commonly experienced symptom with only one-fifth (20.0\%) reported fever during the illness], self-limiting nature of the disease [only $4.8 \%$ required hospitalisation with median recovery time of 2 days] and suspected food item [ $15.7 \%$ reported it to be chicken items while $11.8 \%$ and 9.8\% reported it to be bread and potato items]. Clostridium perfringens and Bacillus cereus well-known food contaminant. The incubation period for Clostridium perfringens varies between 5 to 24 hours while in case of Bacillus cereus it is $8-16$ hours. Clostridium perfringens may grow in food item during cooling, re-heating and holding. The optimum temperature of germination and growth of the spores of the organism is said to be $43-47$ degree Celsius. The most common symptoms associated with both Clostridium perfringens and Bacillus Cereus are food-poisoning is abdominal cramps and diarrhoea with spontaneous recovery within 24-48 hours. $(11,12)$ Clostridium perfringens commonly isolated from contaminated meet, poultries, legumes and gravies while Bacillus cereus commonly grows in meats, vegetables and cereals.(5) Food poisoning outbreaks associated with Clostridium perfringens and Bacillus Cereus are being previously reported in hostel settings.(13) All these points goes in favour of either Clostridium perfringens or Bacillus cereus as most likely causative organism of most of the reported cases in our study.

\section{Conclusion}

One in every four study participants opined to have experienced food poisoning symptoms during the study period. This confirmed the existence of a multi-source food poisoning outbreak in the study population. The causative organism for the most of the food poisoning cases might be either Clostridium perfringens or Bacillus cereus.

\section{Recommendation}

Routine sanitary inspection of all the common kitchens of the institute is warranted to ensure safety of the consumables served by these. Hygiene of food items from handling till serving should be ensured to in curb recurrence of such an outbreak in the present study settings.

\section{Limitation of the study}

We adopted online method of data collection deferring the traditional method of investigating an infectious disease outbreak. This was done for rapid data collection to confirm existence and pattern of the suspected food poisoning outbreak and draw inferences for decision making. Secondly, due to diverse food items and sources, odds of the disease for individual food items could not be calculated. Thirdly, laboratory testing for stool, water and food specimen could not be done due to anonymity of the study subjects. Anonymous data collection was done to ensure maximum enrolment of the population at risk. Lastly, there may be certain other attributes associated with this multi-source food-poisoning outbreak (i.e., personal hygiene of the food handlers and self-catering hostel dweller, sanitation, storage and food handling practices in the common messes etc.) which we did not examine.

\section{Relevance of the study}

The study adopted a rapid online survey to investigate a suspected food poisoning outbreak in hostel settings deferring traditional method of investigating an infectious disease outbreak. By this approach we could able to identify the probable source and aetiology of most of the reported cases.

\section{Authors Contribution}

Conception and design: CS, BB, SP. Acquisition of data: NKG, HH, BB. Analysis and interpretation of data: BB, BNN. Drafting the article: $B B, N K G$. Revised the article critically for important intellectual content: CS, SP, BNN, HH. All 
INDIAN JOURNAL OF COMMUNITY HEALTH / VOL 33 / ISSUE NO 03 / JUL-SEP 2021 authors approved final version of the manuscript to be published.

\section{Acknowledgement}

We would like to acknowledge sincere efforts of all the other faculties, residents and staffs of department community medicine and family medicine of AlIMS-Patna. Without their unconditional support the outbreak investigation would not have been possible.

\section{References}

1. Food safety. World Health Organisation. Available from: https://www.who.int/news-room/fact-sheets/detail/food-safety. (Accessed on 25/09/2021).

2. Arendt S, Rajagopal L, Strohbehn C, Stokes N, Meyer J, Mandernach S. Reporting of Foodborne Illness by U.S. Consumers and Healthcare Professionals. Int J Environ Res Public Health. 2013;10(8):3684-714. doi: 10.3390/ijerph10083684.

3. Havelaar AH, Kirk MD, Torgerson PR, Gibb HJ, Hald T, Lake RJ, et al. World Health Organization Global Estimates and Regional Comparisons of the Burden of Foodborne Disease in 2010. PLoS Med. 2015;12(12):e1001923. doi: 10.1371/journal.pmed.1001923.

4. Food Poisoning Symptoms. Centers for Disease Control and Prevention. 2021 [cited 25 Feb 2021]. Available from: https://www.cdc.gov/foodsafety/symptoms.html . (Accessed on 25/09/2021)

5. Food-Borne Diseases and Food Safety in India. National Centre for Disease Control; 2017. Available from:
[Epidemiological investigation...] | Singh C et al https://www.ncdc.gov.in/linkimages/cdalert03175347761127.pdf (Accessed on 25/09/2021).

6. Foodborne Disease Outbreak | 2011 Case Definition. Available from: https://ndc.services.cdc.gov/case-definitions/foodbornedisease-outbreak-2011/ (Accessed on 25/09/2021)

7. Bintsis T. Foodborne pathogens. AIMS Microbiol. 2017;3(3):529-63. doi: 10.3934/microbiol.2017.3.529.

8. Prajapati $P$, Kaur P, Sidhu T, Singh G, Mehra S, Paul S, et al. Investigation of the food poisoning outbreak in girls hostel of medical college in Punjab. International Journal of Community Medicine and Public Health. 2020;7(8):3166-70. doi: 10.18203/2394-6040.ijcmph20203395.

9. Damodharan J, Rajendiran $P$, Boominathan $C$, Muthiah $M$, Parasuraman G, Dutta R, et al. Investigation of a Food Poisoning Outbreak in a Private Hostel in Kanchipuram District, Tamilnadu. Indian Journal of Public Health Research \& Development. 2020;11(1):75-9. doi: 10.37506/ijphrd.v11i1.333.

10. Vidyashri S, Brundha MP, Priyadharshini R. Analysis on The Individual Perspective on The Flare Up of Food Poisoning Among Hostel Students - A Survey. European Journal of Molecular \& Clinical Medicine. 2021;8(3):3153-64.

11. Bhattacharya A, Shantikumar S, Beaufoy D, Allman A, Fenelon D, Reynolds $\mathrm{K}$, et al. Outbreak of Clostridium perfringens food poisoning linked to leeks in cheese sauce: an unusual source. Epidemiol Infect. 2020;148:e43.

12. Tewari A, Abdullah S. Bacillus cereus food poisoning: international and Indian perspective. J Food Sci Technol. 2015;52(5):2500-11.

13. Grewal VS, Khera A. Outbreak of food poisoning in a working men's hostel: A retrospective cohort study. Medical Journal of Dr DY Patil University. 2017;10(6):517-521. 10.4103/MJDRDYPU.MJDRDYPU_88_17.

\section{Tables}

TABLE 1 UNIVARIATE AND MULTIVARIABLE LOGISTIC REGRESSION ANALYSIS SHOWING DISTRIBUTION AND DETERMINANTS OF FOOD POISONING EVENTS AMONG THE STUDY SUBJECTS AS PER THEIR BACKGROUND CHARACTERISTICS: N=440

\begin{tabular}{|c|c|c|c|c|}
\hline \multicolumn{3}{|c|}{ Total } & \multicolumn{2}{|c|}{ ood poisoning: Yes=105 (23.9\%) } \\
\hline Age in completed years: & $\mathbf{N}(\%)$ & N (\%) & COR $(95 \% \mathrm{Cl})$ & AOR $(95 \% \mathrm{CI})$ \\
\hline $17-19$ & $109(24.8)$ & $24(22.0)$ & Ref. & Ref. \\
\hline $20-22$ & $175(39.8)$ & $36(20.6)$ & $0.92(0.51-1.64)$ & $0.83(0.41-1.71)$ \\
\hline $23-25$ & $100(22.7)$ & $33(33.0)$ & $1.74(0.94-3.23)$ & $1.49(0.53-4.14)$ \\
\hline$\geq 26$ & $56(12.7)$ & $12(21.4)$ & $0.97(0.44-2.11)$ & $0.85(0.22-3.26)$ \\
\hline \multicolumn{5}{|l|}{ Gender: } \\
\hline Female & $177(40.2)$ & $49(27.7)$ & $1.41(0.91-2.20)$ & $1.17(0.10-13.88)$ \\
\hline Male & $263(59.8)$ & $56(21.3)$ & Ref. & Ref. \\
\hline \multicolumn{5}{|l|}{ Designation: } \\
\hline Medical student & $256(58.2)$ & $57(22.3)$ & Ref. & Ref. \\
\hline Nursing student & $46(10.5)$ & $11(23.9)$ & $1.10(0.52-2.30)$ & $1.52(0.04-51.94)$ \\
\hline Intern & $44(10.0)$ & $10(22.7)$ & $1.41(0.82-2.40)$ & $0.57(0.12-2.74)$ \\
\hline Resident doctor & $94(21.4)$ & $27(28.7)$ & $1.03(0.48-2.20)$ & $0.25(0.06-1.08)$ \\
\hline \multicolumn{5}{|l|}{ Residing hostel number: } \\
\hline 1 & $29(6.6)$ & $12(41.4)$ & $5.41(1.32-22.21)$ & $6.51(0.93-45.53)$ \\
\hline 2 & $26(5.9)$ & $6(23.1)$ & $2.30(0.51-10.41)$ & $4.03(0.62-26.24)$ \\
\hline 3 & $73(16.6)$ & $12(16.4)$ & $1.51(0.39-5.83)$ & $1.34(0.32-5.53)$ \\
\hline 4 & $42(9.5)$ & $16(38.1)$ & $4.71(1.22-18.29)$ & $5.31(0.37-76.61)$ \\
\hline 5 & $10(2.3)$ & $2(20.0)$ & $1.92(0.27-13.63)$ & $1.67(0.07-38.04)$ \\
\hline 6 & $44(10.0)$ & $10(22.7)$ & $2.25(0.56-9.09)$ & $0.38(0.01-31.09)$ \\
\hline 7 & $78(17.7)$ & $21(26.9)$ & $2.82(0.77-10.39)$ & $0.83(0.05-13.87)$ \\
\hline 8 & $34(7.7)$ & $5(14.7)$ & $1.32(0.29-6.12)$ & $1.53(0.28-8.24)$ \\
\hline 9 & $51(11.6)$ & $13(25.5)$ & $2.62(0.67-10.19)$ & $2.34(0.55-10.02)$ \\
\hline 10 & $27(6.1)$ & $5(18.5)$ & $1.74(0.37-8.18)$ & $2.15(0.31-15.11)$ \\
\hline 11 & $26(5.9)$ & $3(11.5)$ & Ref. & Ref. \\
\hline \multicolumn{5}{|c|}{ Predominant source of food in last 15 days: } \\
\hline Boys hostel mess & $174(39.5)$ & $35(20.1)$ & $2.01(0.57-7.07)$ & $1.55(0.61-10.72)$ \\
\hline Girls hostel mess & $121(27.5)$ & $37(30.6)$ & $3.52(0.99-12.43)$ & $7.83(1.58-38.79)$ \\
\hline Canteen 1 & $39(8.9)$ & $13(33.3)$ & $4.00(1.01-15.78)$ & $4.83(1.13-20.69)$ \\
\hline Canteen 2 & $23(5.2)$ & $7(30.4)$ & $3.50(0.79-15.58)$ & $3.42(0.69-16.94)$ \\
\hline Restaurant 1 & $56(12.7)$ & $10(17.9)$ & $1.74(0.44-6.92)$ & $1.60(0.36-7.08)$ \\
\hline Others & $27(6.1)$ & $3(11.1)$ & Ref. & Ref. \\
\hline
\end{tabular}




\section{TABLE 2 DISTRIBUTION OF THE STUDY PARTICIPANTS AS THEIR ILLNESS CHARACTERISTICS: N=105}

\begin{tabular}{|c|c|}
\hline Variable & N (\%)/ Mean \pm SD \\
\hline \multicolumn{2}{|l|}{ Presenting symptom: } \\
\hline Abdominal cramps & $31(29.5)$ \\
\hline Bloating & $16(15.2)$ \\
\hline Loose stool & $40(38.1)$ \\
\hline Nausea/ vomiting & $15(14.3)$ \\
\hline Others & $3(3.0)$ \\
\hline \multicolumn{2}{|l|}{ Other symptoms during the illness: (multiple response) } \\
\hline Nausea/ vomiting & $37(35.2)$ \\
\hline Fever & $21(20.0)$ \\
\hline Bloating & $58(55.2)$ \\
\hline Abdominal cramps & $76(72.4)$ \\
\hline Loose stool & $81(77.1)$ \\
\hline Rice water stool & $24(22.9)$ \\
\hline Mucus in stools & $29(27.6)$ \\
\hline Blood in stools & $5(4.8)$ \\
\hline Rectal pain & $23(21.9)$ \\
\hline Weakness & $61(58.1)$ \\
\hline Body ache & $54(51.4)$ \\
\hline Others & $5(4.8)$ \\
\hline Required hospitalisation: (Yes) & $5(4.8)$ \\
\hline Laboratory investigation done: (Yes) & $2(1.9 \%)$ \\
\hline \multicolumn{2}{|l|}{ Treatment or remedies taken during the event: (multiple response) } \\
\hline ORS & $44(41.9)$ \\
\hline Antibiotics & $25(23.8)$ \\
\hline IV fluids & $4(3.8)$ \\
\hline Opioids & $3(2.9)$ \\
\hline NSAIDS & $15(14.3)$ \\
\hline Probiotics & $20(19.0)$ \\
\hline Home remedies & $47(44.8)$ \\
\hline Others $^{*}$ & $9(8.6)$ \\
\hline Duration of illness: (in days) & $2.4 \pm 1.9$ \\
\hline Could suspect food item and/or its source which could have caused the event: (Yes) & $51(48.6)$ \\
\hline \multicolumn{2}{|l|}{ Source of the suspected food item: $(\mathrm{N}=51)$} \\
\hline Boys hostel mess & $12(23.5)$ \\
\hline Girls hostel mess & $20(39.2)$ \\
\hline Canteen 1 & $7(13.7)$ \\
\hline Canteen 2 & $4(7.8)$ \\
\hline Restaurant 1 & $5(9.8)$ \\
\hline Others ${ }^{\#}$ & $3(5.9)$ \\
\hline
\end{tabular}

*Not reported any specific treatment or remedies taken during illness. \#Others include foods from other two restaurants.

Figures

FIGURE 1 LINE DIAGRAM SHOWING TREND OF THE REPORTED FOOD POISONING CASES IN TOTAL AND AS PER THEIR PREDOMINANT SOURCE OF FOOD DURING THE STUDY PERIOD: N=105

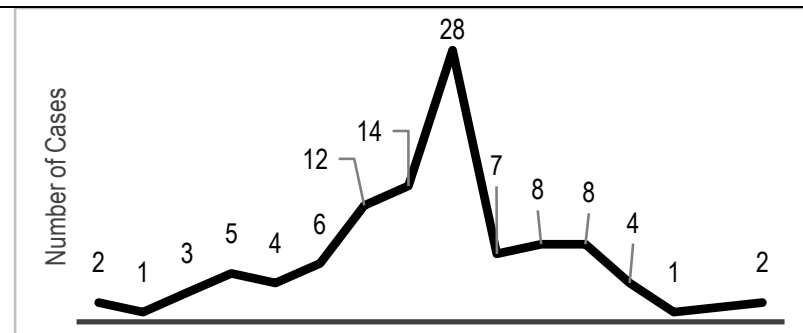

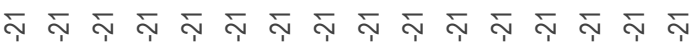

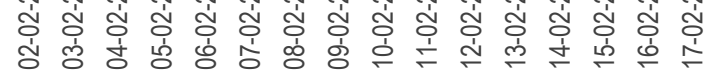

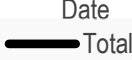

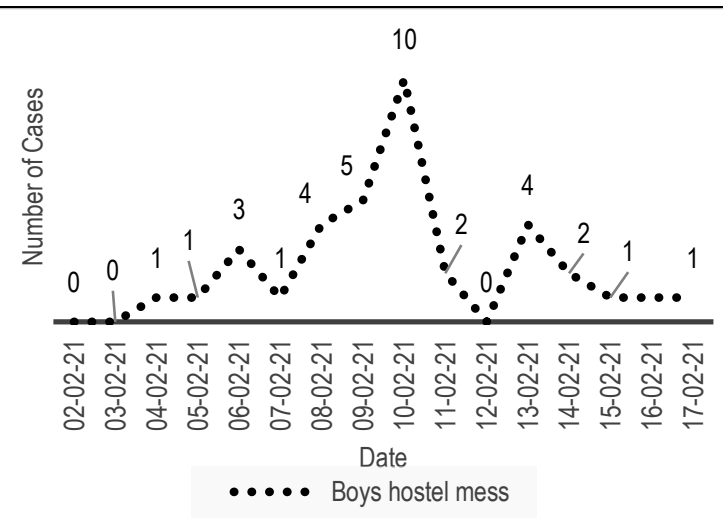

-.... Boys hostel mess 


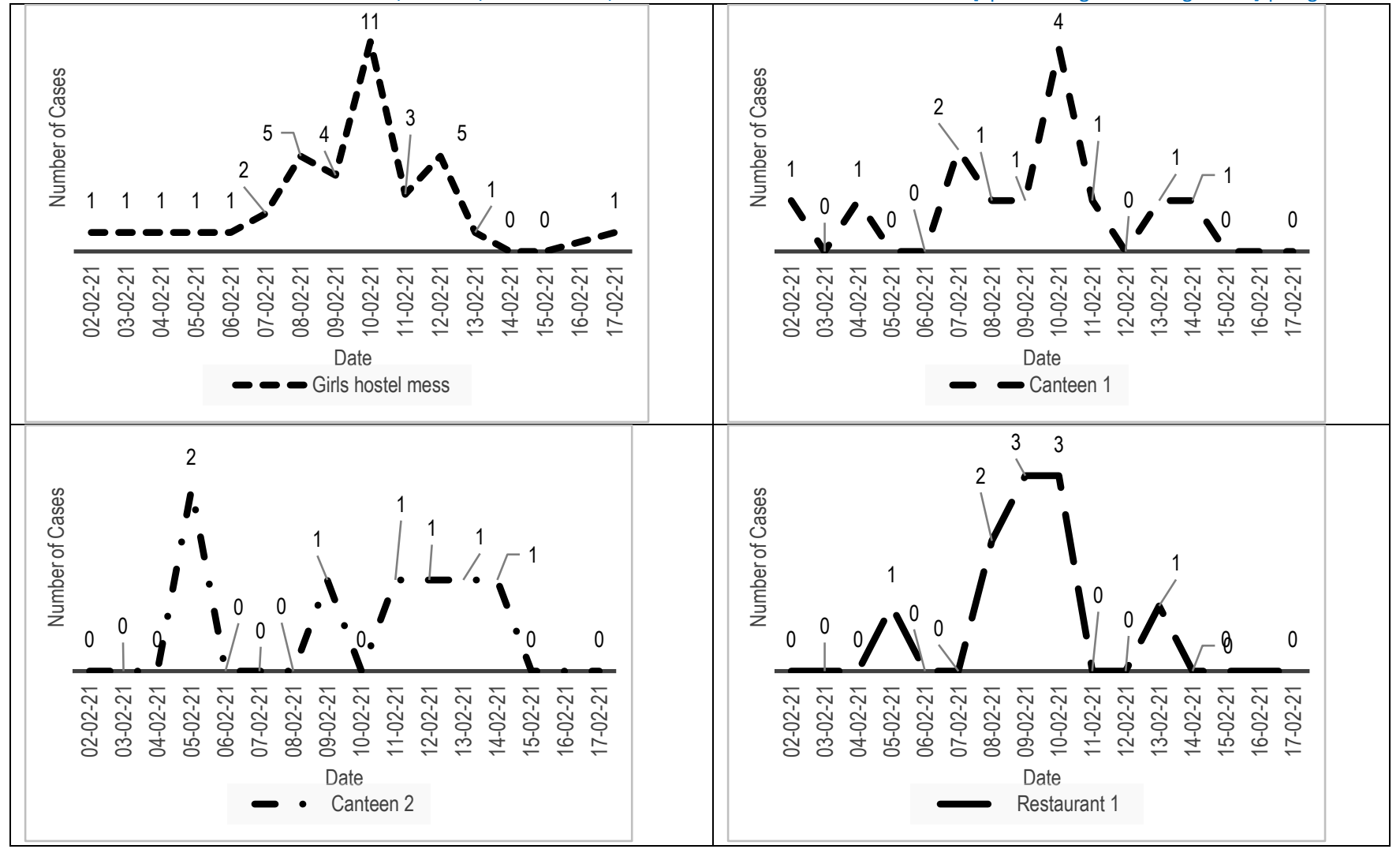

FIGURE 2 BAR CHART SHOWING DISTRIBUTION OF THE STUDY PARTICIPANTS AS PER TIME INTERVAL BETWEEN CONSUMPTION OF SUSPECTED FOOD ITEM AND ONSET OF SYMPTOMS (INCUBATION PERIOD): $\mathbf{N = 5 1}$

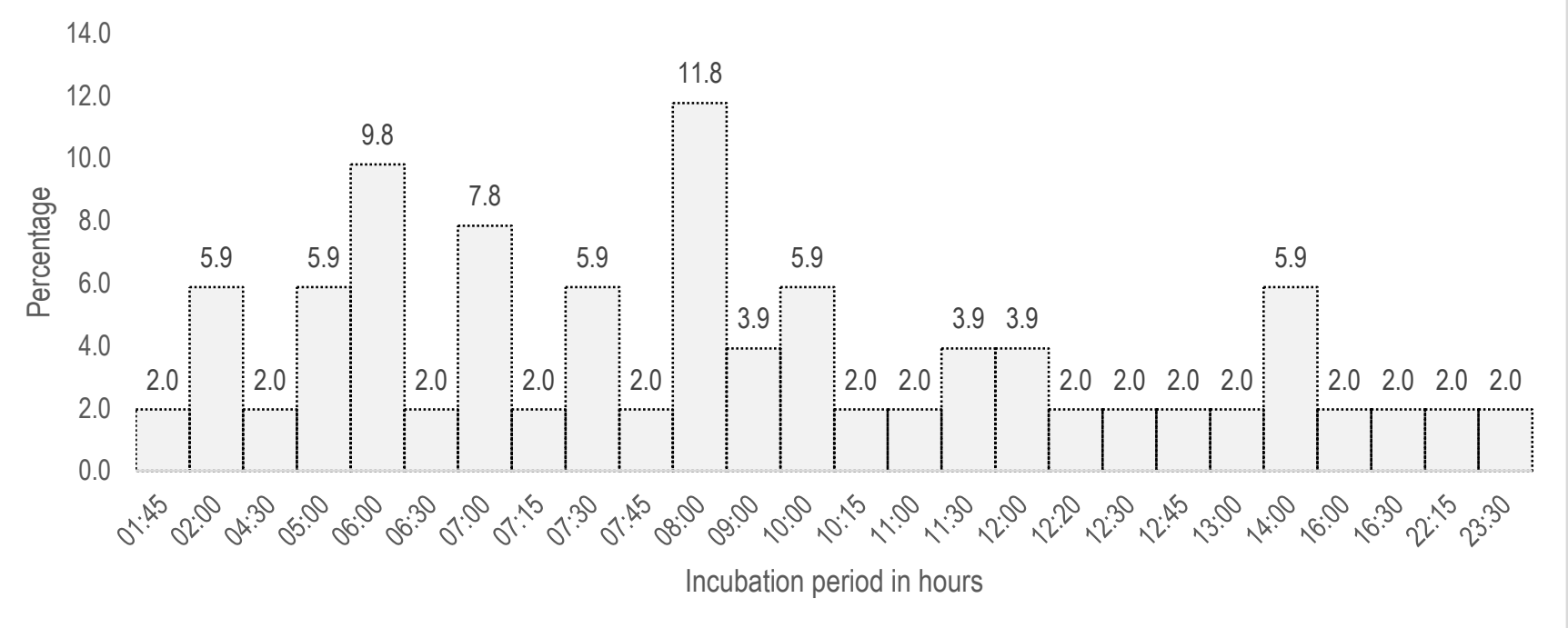

